\title{
THERMAL BRIDGES IN BUILDING ENVELOPES - AN OVERVIEW OF IMPACTS AND SOLUTIONS
}

\author{
A. ALHAWARI, P. MUKHOPADHYAYA* \\ University of Victoria, Canada \\ *E-mail: phalguni@uvic.ca
}

\begin{abstract}
Increasing building energy performance has become an obligatory objective in many countries. Thermal bridge is a major cause of poor energy performance, durability, and indoor air quality of buildings. This paper starts with a review of thermal bridges and their negative impacts on building energy efficiency. Based on published literatures, various types of building thermal bridges are discussed in this paper, including the most effective solutions to diminish their impacts. In addition, various numerical and experimental studies on the balcony thermal bridge are explored. Results show that among all types of thermal bridges, the exposed balcony slab produces the most challenging thermal bridging problem where an integrated thermal and structural design is required. Using low thermal conductivity materials in building construction could help in reducing the impact of thermal bridges. Finally, further investigations are needed to develop more innovative and effective solutions for the balcony thermal bridge.
\end{abstract}

Keywords: thermal bridges, thermal break, energy performance, balcony

\section{Introduction}

Globally, over the past decades, demand for energy is increasing rapidly every year and a significant portion of this demand is consumed by residential buildings sector. After the energy crisis in the 1970s and the desire to diminish the environmental pollution problem, search for alternative resources to crude oil, such as solar and wind energy, had become a priority of many nations. Simultaneously, number of regulations have been adapted to minimize the energy consumption in different sectors [1]. Because of the extremely cold climate in Canada, residential buildings sector consume about $17 \%$ of total energy usage and space heating consumes about $63 \%$ of the total energy consumed in residential buildings sector [2]. The building envelope has some areas with low thermal resistance through which the heat can transfer easily, for example, windows, doors, skylights, and thermal bridges. Thermal bridges are defined as areas of building envelope with very low thermal resistance, usually as a result of a penetration through building insulation lay- ers. According to Passive House standards, the total heat transfer coefficient of opaque wall components in cool climate zone must not exceed $0.15 \mathrm{~W} /\left(\mathrm{m}^{2} \mathrm{~K}\right)$ [3]. Various types of high energy efficient walls, roofs, and windows have been developed to reduce the buildings energy consumption. In addition, different advanced thermal insulation materials have been integrated in building envelope constructions such as phase change material (PCM), aerogel blanket insulation, vacuum insulation panel (VIP) etc. to reduce heat transfer through exterior building envelopes [4].

\section{Consequences of thermal bridges}

After windows and exterior doors, the second essential cause of heat loss in the high-rise buildings is non-insulated concrete slabs such as balconies [5]. The thermal bridges in buildings cause several negative consequences: high energy consumption for heating and cooling process, non-compliance with energy codes requirements, and uncomfortable spaces due to cold interior surfaces. Furthermore, they cause condensa-

This is an open-access article distributed under the terms of the Creative Commons Attribution-NonCommercial 4.0 International License (https://creativecommons.org/licenses/by-nc/4.0/), which permits unrestricted use, distribution, and reproduction in any medium for non-commercial purposes, provided the original author and source are credited, a link to the CC License is provided, and changes - if any - are indicated. 
tion on cold surfaces that may lead to dampness and mold growth, associated with health concerns caused by poor indoor air quality. Thermal bridging through walls and ceiling studs causes low temperature areas along these assemblies that leads to wall staining, which is also called "ghosting" [6]. Adding more insulation layers to the building envelope while disregarding the impact of thermal bridges may not lead to a significant reduction in the heat losses, however it may increase the thermal bridging impact beside the augmentation in cost of construction $[7,8]$.

Disregarding impacts of thermal bridges but adopting highly efficient windows and well-insulated walls will not produce an optimum reduction in the building energy usage. The building thermal bridges cause an increase of about $30 \%$ in the space heating load $[1,3,9]$. Neglecting the major building thermal bridges, such as balconies, can result in an underestimation of $20 \%$ to $70 \%$ of the total heat flow through the building envelope [7]. Unaccounted effects of thermal bridges in some buildings can cause an increase in thermal loads by up to $35 \%$ than preliminary calculations [1]. Thermal bridge can cause a reduction in the total thermal resistance of the clear wall field by about $40 \%$ [10]. Solid metal profiles, that used to fix the building envelopes' insulation layers, diminish the thermal resistance of the assembly to half value, so they are a major cause of thermal bridging [3].

\section{Types of building thermal bridges}

Thermal bridge exists in areas where the heat transfers across the building envelope components, because of the discontinuity in thermal insulation layers [5]. There are different areas of the building envelope with high thermal transmittance (low thermal resistance), through which heat can pass more easily, such as balcony connections, windows frame, exterior wall corners, floor supports, and anchors [11]. The thermal resistance of some of these areas can be increased by adding more insulation materials; on the other hand, some of thermal bridges cannot be solved by increasing the thickness of the insulation layer, for example, wall penetrated by balconies. The amount of heat transferred through the common thermal bridges may exceed the amount of heat transferred through the insulated assemblies [11]. Following is a brief description of the common types of building envelope thermal bridges [12].

\subsection{Constructional/structural thermal bridges}

As presented in Fig. 1, structural thermal bridges exist where a penetration occurs in the insulation layer of the exterior building envelopes. They are very common and easy to identify in building envelope be- cause of their significant negative impact. These types of thermal bridges cause a discontinuity in the insulation layers, for example, projection of balconies, slab edges of buildings, and floor supports.

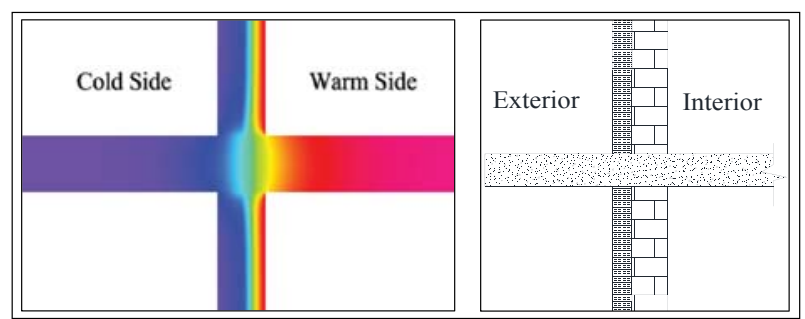

Fig. 1. Schematic constructional/structural thermal bridges

\subsection{Geometrical thermal bridges}

As shown in Fig. 2, these types of thermal bridges exist in the envelopes of building where a difference occurs between the internal thermal absorbing area and external thermal dissipating area. For example, edges, corners of buildings, and window perimeters. The corner thermal bridge occurs at the junction between wall to wall, wall to roof, and wall to floor. These types do not form a discontinuity in the insulation layers.

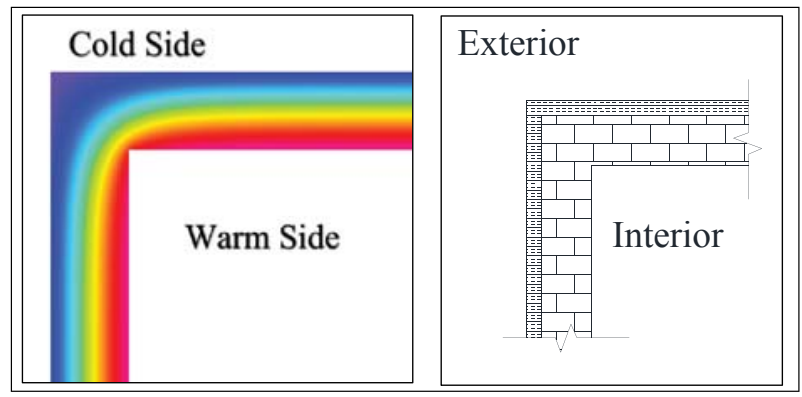

Fig. 2. Schematic of a geometrical thermal bridge

\subsection{Systematic thermal bridges}

As shown in Fig. 3, these types usually appear in a certain series in the building assembly, such as wall's wood or metal studs, and concrete block webs. The joints in walls play a major role of heat loss and gain between indoor and outdoor environments, which is the major cause of the "ghosting" phenomenon.

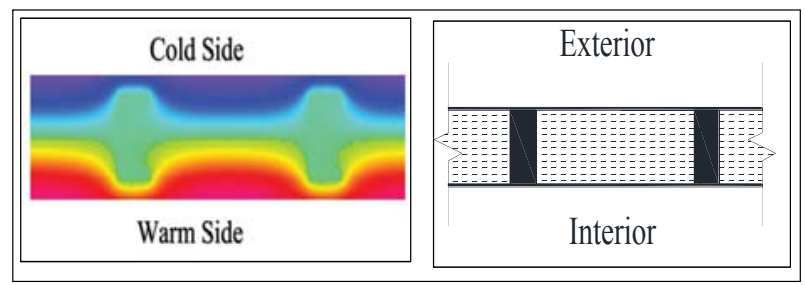

Fig. 3. Schematic of a systematic thermal bridges 


\section{Linear and point thermal transmittance}

The linear thermal transmittance is defined as the difference between the heat flow through a building assembly with thermal bridges, such as balconies, and the amount of heat transferred through a clear building assembly divided by the effective length of the thermal bridges (Fig. 4). The point thermal transmittance differs from the linear thermal transmittance. The effective length of thermal bridges is not required to calculate the point thermal transmittance. For instance, anchors, and floor supports considered as point thermal bridges and their thermal effect considered as the point thermal transmittance.

The heat transfer across the thermal bridges can be calculated by knowing the linear and/or point thermal transmittance of the thermal bridge as described in following equations:

$$
\begin{gathered}
Q_{0}=U_{0} A_{0}\left(T_{\text {on }}-T_{\text {out }}\right), \\
U_{0}=1 / R_{0}, \\
R_{0}=1 / h_{\text {in }}+x_{n} / k_{n}+1 / h_{\text {out }}, \\
L_{3 \mathrm{D}}=Q_{t} / \Delta T, \\
\Psi=\left(L_{3 \mathrm{D}}-U_{0} A_{0}\right) / l, \\
\chi=L_{3 \mathrm{D}}-U_{0} A_{0}, \\
Q_{t}=Q_{0}+Q_{t b}, \\
Q_{t b}=\left(\sum_{i=1}^{I} \Psi_{i} l_{i}+\sum_{j=1}^{J} n_{j} \chi_{j}\right)\left(T_{\text {in }}-T_{\text {out }}\right),
\end{gathered}
$$

$$
Q_{t}=\left(U_{0} A_{0}+\sum_{i=1}^{I} \Psi_{i} l_{i}+\sum_{j=1}^{J} n_{j} \chi_{j}\right)\left(T_{\text {in }}-T_{\text {out }}\right),
$$

where

$Q_{0}$ is the amount of heat transfers across the clear wall [W],

$U_{0}$ is the thermal transmission coefficient of the clear wall $\left[\mathrm{W} / \mathrm{m}^{2} \cdot \mathrm{K}\right]$,

$A_{0}$ is the surface area of the clear wall $\left[\mathrm{m}^{2}\right]$,

$T_{\text {in }}, T_{\text {out }}$ are indoor and outdoor temperatures [K],

$R_{0}$ is the thermal resistance of the clear wall $\left[\mathrm{m}^{2} \mathrm{~K} / \mathrm{W}\right]$,

$h_{\text {in }} / h_{\text {out }}$ is the indoor/outdoor convection heat transfer coefficient $\left[\mathrm{W} / \mathrm{m}^{2} \cdot \mathrm{K}\right]$,

$k_{n}$ is the conduction heat transfer coefficient for $n$ assembly materials $[\mathrm{W} / \mathrm{m} \cdot \mathrm{K}]$,

$x_{n}$ is the thickness for $n$ clear wall layers [m],

$\Psi$ is the linear thermal transmission coefficient $[\mathrm{W} / \mathrm{m} \cdot \mathrm{K}]$,

$\chi \quad$ is the point thermal transmission coefficient $[\mathrm{W} / \mathrm{K}]$,

$L_{3 \mathrm{D}}$ is the thermal coupling coefficient from 3-D calculation $[\mathrm{W} / \mathrm{K}]$,

$Q_{t b}$ is the amount of heat transfers across the assembly through the thermal bridge [W],

$Q_{t}$ is the total amount of heat transfers across the assembly [W],

$l$ is the effective length of thermal bridge [m],

$n$ is the number of point thermal bridges in the assembly.

Regression models have been developed to estimate the linear thermal transmittance of three common thermal bridges in the building envelope: slab on grade floor to wall intersection, floor to wall intersec-

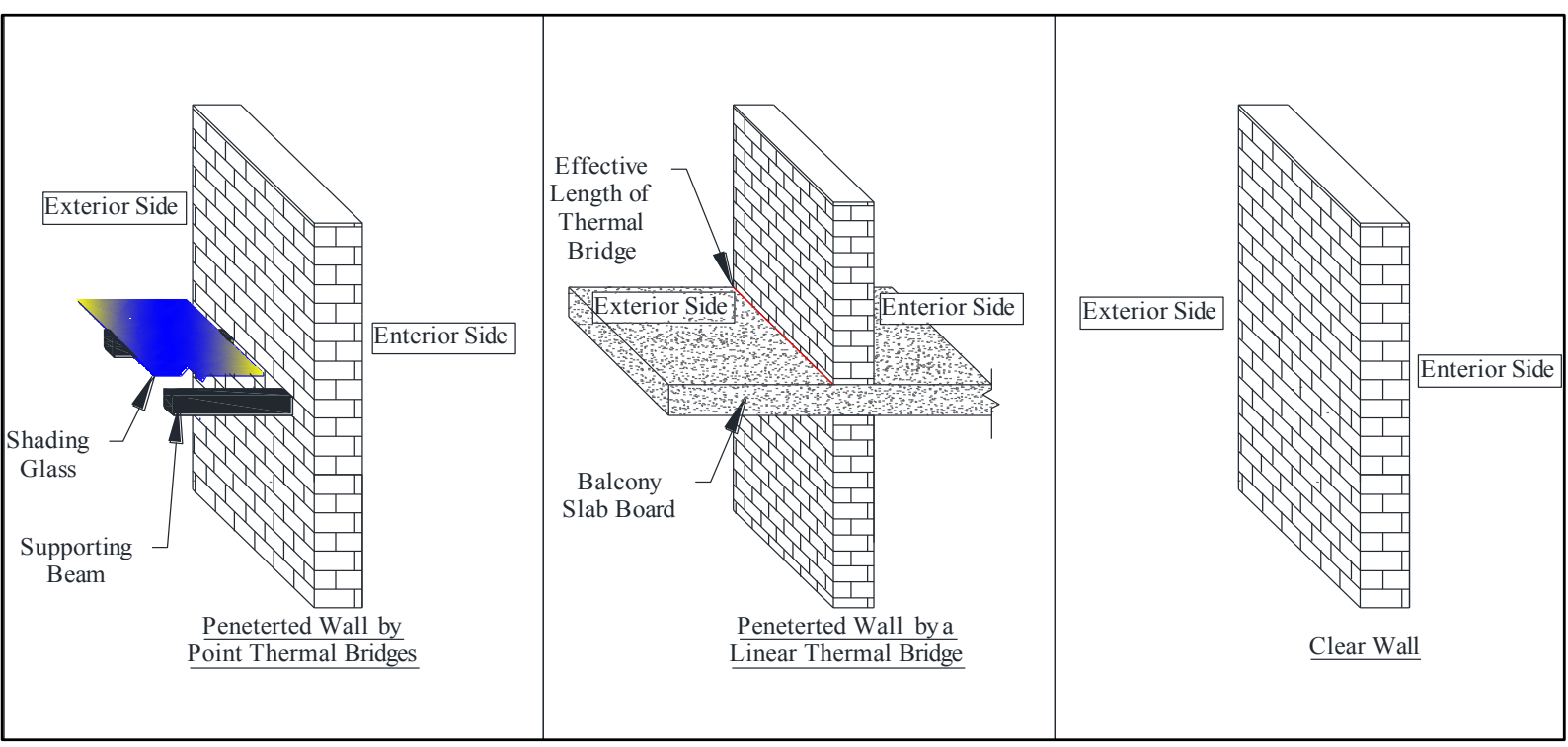

Fig. 4. Sketches of different wall configurations 
tion, and roof to wall intersection [8]. These models can predict the value of linear thermal transmittance of the three aforementioned thermal bridges with a relative error of less than 5\% compared to the results that were calculated using computer software. In Europe, there are three different techniques used to estimate the thermal transmittance coefficient [13]. Selecting the thermal transmittance default values from the European Standard EN ISO 14683 [14] is the most common practice. However, using the default values from the standard may not give a precise estimation of the thermal bridge effects because of the complexity in constructions of some envelope elements. In addition, applying the thermal transmittance default values may not give an accurate estimation of thermal calculations for North American buildings. This inaccuracy occurs because of the variances in the design and the construction materials used in European buildings. The common construction materials in Europe is concrete or masonry that ensures no interference between more than one type of thermal bridges; however, this is not the case in the North American buildings construction [10].

\section{Approaches to reduce the impact of thermal bridges}

As mentioned earlier, building envelopes have different types of thermal bridges that cause a rise in the energy consumption, because of the increase in heat loss or gain across the exterior building envelopes. As well, they may result in a problem of moisture condensation and mold growth on interior surfaces. Meeting the requirements of energy code regulations, ensuring suitable mechanical and thermal design, and reducing the proportion of energy loss and gain through thermal bridges have become a priority for many energy and building researchers. Therefore, number of numerical and experimental studies have been published on different types of thermal bridges with the aim to reduce their negative thermal impacts. Some thermal bridging problems can be solved by adding additional insulating barrier layers to ensure the insulation continuity in order to disrupt the heat transfer, while others require specific approaches to reduce their impacts.

\subsection{Wall-to-roof interface}

To solve the issues associated with geometrical thermal bridges, the solution depends on the design of building assemblies and how they interface with each other. In the case of wall to roof interface (Fig. 5) where the wall rises above the roof level, an insulation layer on the wall to roof interior corner is needed to prevent the thermal bridging [11].

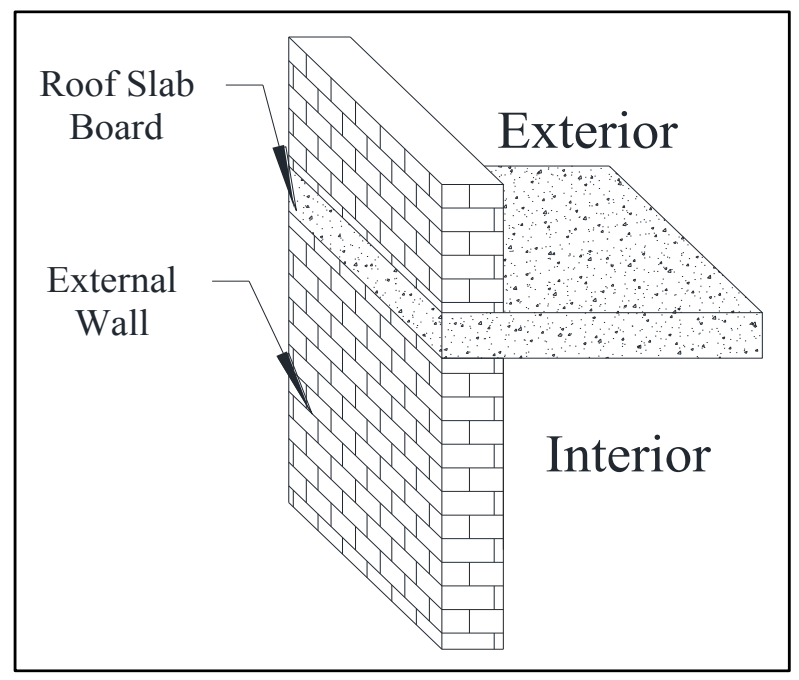

Fig. 5. Sketch of wall to roof interface

\subsection{Window perimeters}

A window offset (Fig. 6) can be considered as an essential thermal bridge. In some architectural design, the frames of windows are shifted outside to add some flush to the buildings. This shift causes a discontinuity in the building envelope insulation layer where the heat can transfer around the window frame especially in metal constructions. To eliminate heat from escaping through the window perimeter, an insulated panel is needed. Adding an insulation coat made of silica aerogels $(k=0.03-0.04 \mathrm{~W} / \mathrm{m} \cdot \mathrm{K})$ to the window pe-

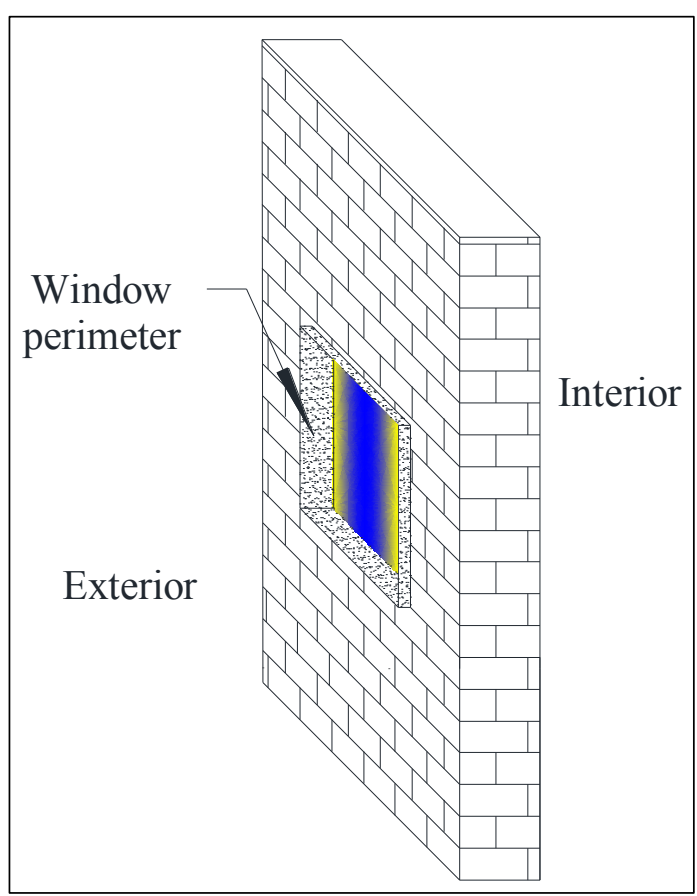

Fig. 6. Sketch of window perimeter 
rimeter causes up to a $50 \%$ reduction in the energy loss caused by windows' offset thermal bridges [15].

\subsection{Interface between building assemblies}

Wall-to-wall thermal bridges (Fig. 2) commonly exist between any two perpendicular walls because of the difference in interface region area from inside to outside. The adequate solution to this type of thermal bridge is adding additional insulation to the interface region. Furthermore, overlying exterior and interior insulation or insulating different planes of the wall is needed to ensure continuous thermal barrier [11].

\subsection{Sun-shade structures}

The sun-shade elements (Fig. 7) are used in building constructions to reduce the radiation heat gain during the summer. Sometimes, these elements have a negative impact on thermal loads during the winter. Isolating these elements from the building envelope is required to diminish heat bridging from warm indoor to cold outdoor environments. Using lapped insulation at anchors of the sun-shades is a good way to eliminate these type of thermal bridges [11].

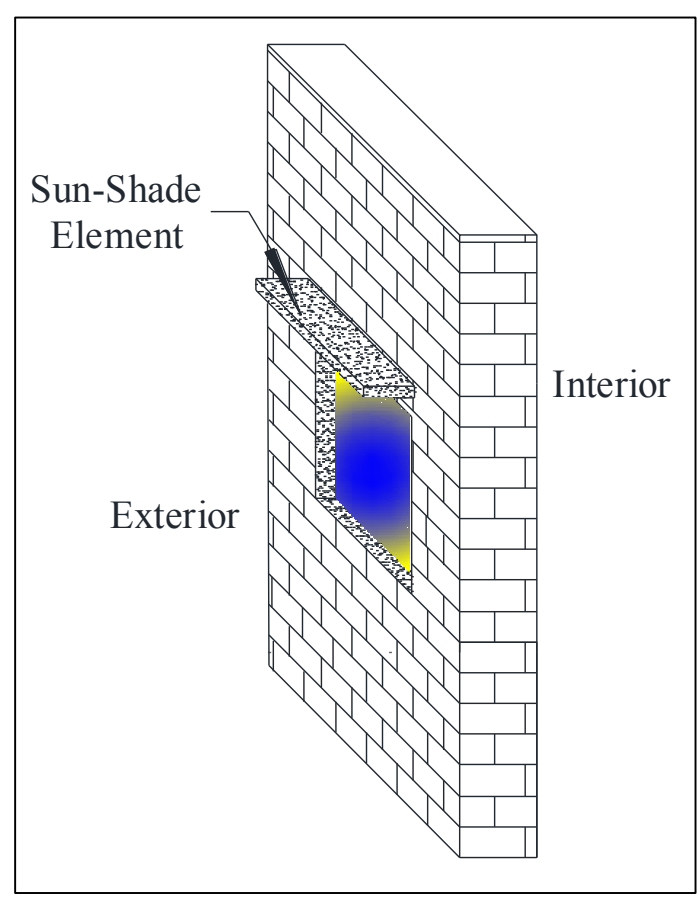

Fig. 7. Sketch of sun-shade element

\subsection{Exterior wall studs}

The thermal bridge caused by studs (Fig. 3) exists when the insulation is applied only for the area between studs. In the case of metal construction, using wood studs instead of steel will reduce heat loss; otherwise, an exterior insulation layer is needed [16].
Increasing the space between the studs by $20 \mathrm{~cm}$, in case of not adding an external insulation layer, will cause an increase in the overall thermal resistance of the wall by $25 \%$ [17].

\subsection{Balconies extended slab}

In general, the thermal bridging through the balcony slab (Fig. 1) is considered as the most challenging problem [18]. Among all thermal bridge types, the balcony thermal bridge causes the highest percentage of energy loss. The balcony slab board penetrates the barrier layers of the building envelope and creates a direct connection (i.e., heat flow path) between spaces with different thermal conditions. The balcony slabs work as "heat transfer fins" in buildings [16]. Compared with all other types of thermal bridges, balcony thermal bridges have a significant negative impact on energy performance because they present a large cross-sectional area ratio of exterior building envelopes [5]. Because of its greater impact on energy performance of buildings, the next section will concentrate on solutions of this type of thermal bridges.

\section{Minimizing impacts of balcony thermal bridges}

Researchers working on thermal bridging mostly focused on addressing the importance and the calculation methods to determine the amount of heat transferred through building thermal bridges. After demonstrating the negative impacts of thermal bridges on buildings energy performance and occupants' comfort, researchers started focusing on finding solutions for the issue. So far, a number of numerical and experimental research studies were published on finding solutions to diminish the heat loss across the balcony slabs.

Wakili et al. [18] developed a balcony board sample with a thermal break made of glass fiber reinforced polymer (GFRP) as compression elements. The thermal performance of the new balcony board was analyzed numerically by using the TRISCO 3D computer program [19]. A specimen of the new balcony board and a wall made of exterior insulated brick ( $U$ value $=0.2 \mathrm{~W} / \mathrm{mK}$ ) were built and tested in a hot-box $\left(\Delta T=30^{\circ} \mathrm{C}\right)$. Both numerically and experimentally, the linear thermal transmittance and the temperature of the inner corner between the lower surface of the balcony and the wall surface were measured. Then the results were compared with conventional balcony board (balcony slab without thermal break). Both the experimental and the numerical analysis gave almost same results for temperature profile along the specimen surface. Comparing the inside corner temperature in case of the new balcony board and the con- 
ventional balcony showed that using the thermal break caused a rise in the inside corner temperature by up to $4{ }^{\circ} \mathrm{C}$ depending on the structural and the strength of the innovative thermal break. The study demonstrated the positive influence of thermal break on the linear thermal transmittance. The innovative thermal break caused a decrease of about $60 \%$ in the linear thermal transmittance compared to the linear thermal transmittance of the conventional balcony board.

Karabulut et al. [20] studied the effects of insulating the surfaces of two different thermal bridge types (intermediate floor beam wall, and extended balcony board). This study focused on the impact of external and internal insulation layers and the effect of the insulation layer thickness on the thermal bridging. Thermal analyses in this study were done by using ANSYS FLUENT simulation tool [21]. The specimen wall was built of brick that is penetrated by the concrete slab with a $35^{\circ} \mathrm{C}$ temperature difference across the wall. The impact of insulating the building envelope was presented by measuring the temperature variation along the penetrated wall. The internal insulation scenario produced a $65 \%$ to $80 \%$ reduction in the heat flux through the wall depending on the thickness of the insulation material. However, the case of internal insulation did not cause any reduction in the heat flux through the concrete slab. Therefore, the interior insulation was not a good solution to eliminate the thermal bridging. The researchers studied the effect of exterior insulation on the heat flux through the penetrated wall. In this scenario, the inner surface temperature did not drop as it did in the case of internal insulation. The heat flux through the wall was very low compared to the interior insulation scenario, which means the external insulation layer has a good effect in reducing the heat transfer. Changing the thickness of the insulation layer had a significant influence on the inner temperature variation and the heat flux through the assembly. The influence of covering the balcony slab with insulation material with various thicknesses was also investigated. In comparison with the uninsulated balcony board, this approach caused an important change in temperature variation and heat flux through the inner surface of the assembly. The lowest surface temperatures were recorded at the interior corner where the reinforced concrete component joined the wall assembly.

In 2016, the same research group published another research study [22]. The objectives of this research were the same as the previous one, but the study was extended to different building and insulation materials. The new study emphasized the effects of different configurations of insulation layers applied on the same building geometry. The conclusion of this study supported the results from the previous research, i.e., the importance of adding insulation layers to the building envelope and the effectiveness of external insulation.

In recent years, a number of studies were carried out to investigate the significance of using a commercially available thermal break products (Fig. 8) [23] to reduce the heat loss through the balcony thermal bridge. A typical commercially available thermal break product is built by using different insulation materials such as extruded/expanded polystyrene or mineral wool and contains reinforcing bars to deal with shear, tensile, and compression forces [23]. A Canadian study [5] investigated the importance of installing the commercially thermal break in the construction of the balcony slab. The numerical analysis was carried out using HEAT 3 software [24]. The study predicted that using the thermal break would produce an in-

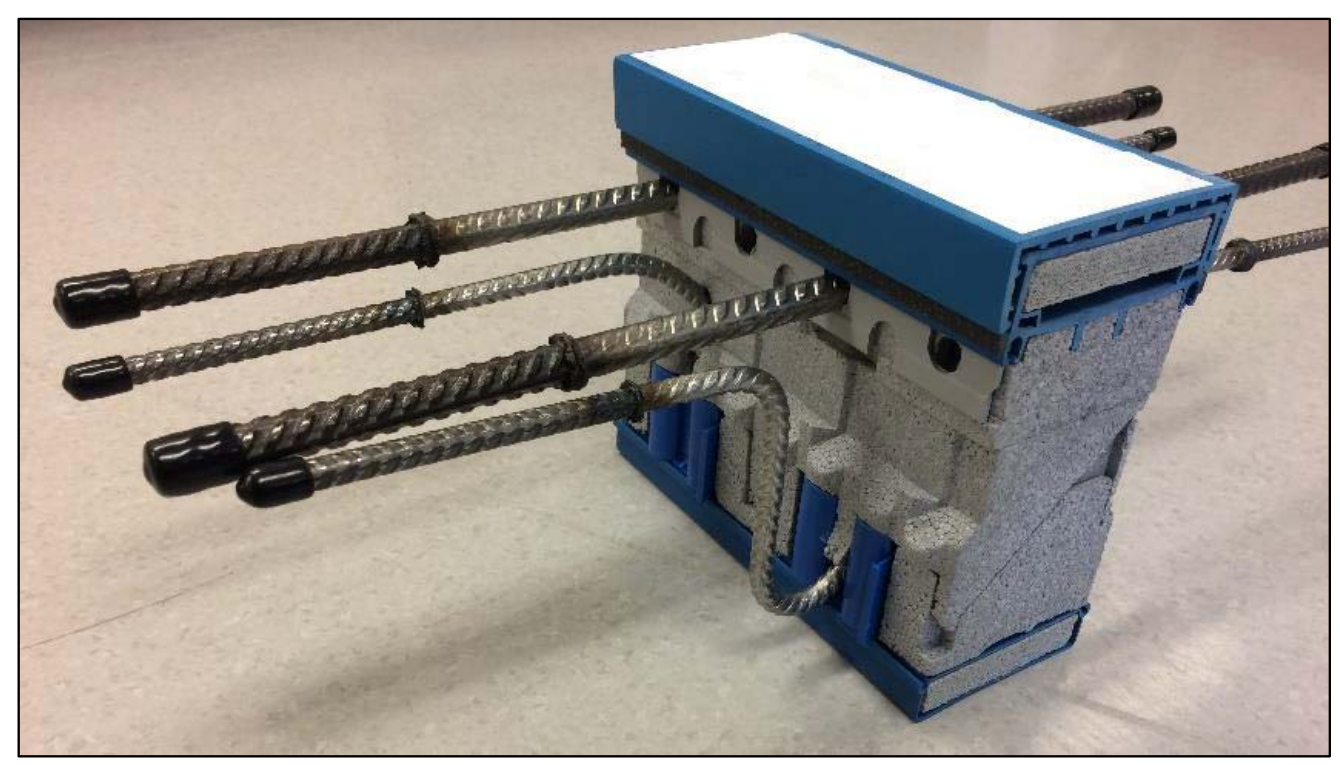

Fig. 8. A commercially available thermal break product 
crease in the internal slab-wall corner temperature up to $4.5^{\circ} \mathrm{C}$ higher than the non-thermally broken balcony. The study concluded that using the thermal break would cause a $7 \%$ to $8 \%$ reduction in space heating energy demand.

A study by Ge et al. [25] on a twenty-six-story building, located in Toronto, Canada, investigated the impact of the commercial balcony thermal break on the internal slab surface temperature of seven different wall configurations, using simulation tool THREM [26]. Furthermore, the researchers presented the effects of the thermal break on the building heating and cooling loads by using eQuest energy simulation tool [27]. The study concluded that installing the traditional balcony thermal break caused a $4.1{ }^{\circ} \mathrm{C}$ to $6.4{ }^{\circ} \mathrm{C}$ increase in the internal slab temperature, depending on the wall assembly configuration. The thermal break caused a $5 \%$ to $13 \%$ reduction in the annual heating energy consumption, and less than $1 \%$ reduction in annual cooling energy consumption. The performance of thermal break is higher when window to wall area ratio is reduced, walls are well-insulated, and other types of wall thermal bridges are eliminated.

A field study [28] evaluated the influence of thermal break in the balcony construction on the thermal performance and energy saving of high-rise multi-unit residential buildings located in Chicago, IL, USA. The study was done by installing thermocouples on both the slab board of a thermally broken balcony and the conventional balcony slab (non-thermally broken balcony) to measure the temperature gradient. During the cold season, the temperature readings indicated that temperature gradient through the thermally broken balconies was $2.5^{\circ} \mathrm{C}$ to $4.5^{\circ} \mathrm{C}$ lower than those of the conventional balconies, which means lower heat losses through the building envelope. Implementation of the thermal break caused a reduction in the building energy consumption by up to $3 \%$. In a 20 -storey building with continuous balconies geometry around the building perimeter on each storey, the annual energy saving cost can be up to 6000 USD based on utilities rate of Illinois, USA.

Goulouti et al. [29, 30] studied the impact of replacing the stainless-steel bars in the conventional thermal break with fiber-reinforced polymer materials that have low thermal conductivity, about 170 times less than stainless-steel thermal conductivity. The innovative thermal break was built in a PVC box filled with aerogel materials $(k=0.013 \mathrm{~W} / \mathrm{m} \cdot \mathrm{K})$ to ensure high thermal resistivity. The tension stainless-steel bars in the conventional thermal break were replaced by the aramid fiber-reinforced polymer bars. The compression bars were replaced by glass fiber-reinforced polymer bars attached to a hexagonal foam sandwich to transmit the shear force. Generally, this study focused intensively on the structural performance of the innovative thermal break. ANSYS FLUENT software was used to investigate the thermal performance of the new thermal break. The study concluded that thermal losses diminished by $41 \%$, in the case of ideal building envelope that has the lowest energy consumption. In addition, the study showed that very low values of linear thermal transmittance could be achieved $(\Psi<$ $0.15 \mathrm{~W} / \mathrm{m} \mathrm{K}$ ).

Murad et al. [31] studied the impacts of including insulated concrete curb, which is made of $25.4 \mathrm{~mm}$ Extruded and Expanded Polystyrene (XPS and EPS), underneath the sliding door of the balcony. Eight different scenarios were thermally investigated by using THERM simulation tool. The commercial balcony thermal break was one of the scenarios that was used for comparison. The objectives of this study were to measure the interior wall-balcony corner temperature and the distance from the sliding door to the point where the slab surface temperature reaches the space temperature. The study concluded that the installation of the insulated concrete curb under the sliding balcony door increased the interior temperature, and reduced the distance from the sliding door to the point of the same indoor temperature. These results improved when the insulated curb was combined with using the commercial balcony thermal break.

Another comprehensive research study [5], evaluated the influence of different building design parameters, such as balcony slab thickness, projection span of the balcony, effects of floor finishing, and impact of radiant heating system, on the equivalent thermal resistance value of the wall assembly (Eq. $R$ value). The study indicated that an increase of 2 inches to the thickness of the balcony slab would cause about $12 \%$ reduction in the wall Eq. $R$ value. The change in the balcony projection depth had insignificant impact on wall Eq. $R$ value. The indoor floor finishing and radiant in-floor heating system had almost no effects on the wall Eq. $R$ value. This study also presented various solutions to reduce the balcony thermal bridging, such as balcony structure cut-outs with and without insulation, concentrated reinforced steel bars with and without insulation, insulated outer balcony surfaces, and installed conventional thermal break. HEAT3 software was used to analyze the performance of the above solutions. The research concluded, in the case of well-insulated walls, the first two scenarios made no positive impact on the wall assembly Eq. $R$ value except when the insulation was added to the section area that is free of steel bars. In these cases, compared to the traditional balcony slab case, the wall Eq. $R$ value would increase by around $50 \%$. Insulating the outer surface of the balcony made a significant increase in the wall Eq. $R$ value by around $60 \%$. Using the commercial thermal break caused an increase in the wall Eq. $R$ value to double value. 
A case study by Ge and Baba [32] presented the effect of the building thermal bridges on the energy consumption of a two-story residential building. Two different climates were chosen, Quebec City, QC, Canada as a cold climate location, and Phoenix, AZ, USA as a hot climate location. A whole building energy analysis was performed using WUFI Plus program [33]. The thermal bridge impact was modeled using three different methods, direct 3D simulation method, equivalent $U$ value method, and equivalent wall method. These three methods were used to calculate the difference in annual heating and cooling loads. In comparison to using the 3D simulation method in calculating the annual heating and cooling loads, the study indicated the followings: in cold climate, use of equivalent $U$ value method caused an underestimation of $8 \%$ to $13 \%$, and use of equivalent wall method caused an underestimation of $4 \%$ to $9 \%$; while in hot climate, use of equivalent $U$ value method and equivalent wall method caused an underestimation of $17 \%$, and $14 \%$, respectively.

Another study reported by Baba and Ge [34] investigated the effect of the balcony thermal bridge on the energy performance of a high-rise building in different locations in Canada. The researchers studied the impact of the balcony thermal bridge on the building thermal loads by using the equivalent $U$ value method and a simulation tool, WUFI Plus program. The effect of implementing the commercial balcony thermal break on the building thermal loads was investigated. The study presented effects of the balcony thermal bridge on three different configurations of balcony slabs. The researchers discovered that the divergence in calculated annual thermal loads between the two used methods was higher in the milder climate. The thermal break reduced the energy consumption in the heating process by $7.1 \%$ to $8.8 \%$, and its effectiveness improved in well-insulated building envelopes. The thermal break reduced the difference between the results of the methods. This study demonstrated the importance of the balcony thermal bridge and the effect of increasing the balcony slab ratio on the building thermal loads, particularly the heating load.

A numerical and experimental analysis study conducted by Dikarev et al. [35] investigated the thermal effect of the balcony thermal bridge on the temperature gradient in the interior floor and roof slab surfaces. The researchers studied the impact of implementing the commercial balcony thermal breaks on energy loss through slab boards that penetrate the building envelopes. Two samples were tested; one was a wall penetrated by slab board (conventional case), while the other sample was a wall penetrated by a thermally-broken slab board (thermal break case). Both samples were placed in a guarded hot box to measure the temperature gradient along the slab board using a number of thermocouples. Furthermore, a three-dimensional steady-state numerical approach was performed using ANSYS FLUENT. The numerical analysis was applied to validate and compare the experimental analysis. The conclusion of this study was that the balcony commercial thermal break has a significant influence in reducing the energy loss through the balcony slab board. This thermal break produced an increase in temperature of $8^{\circ} \mathrm{C}$ higher than the conventional case at a particular point on the slab board.

A research study by Real et al. [36] investigated the use of structural lightweight aggregate (SLWA) in concrete instead of the normal weight aggregate (NWA) to diminish the negative impact of thermal bridges in the building envelopes. Because of the porosity in the composition of SLWA, this aggregate has a low thermal conductivity compared to NWA. It was observed that an increment of $1 \%$ in aggregate porosity caused a reduction in its thermal conductivity by $0.6 \%$. This advantage of SLWA had been tested numerically by THERM software on four different types of structural lightweight aggregate concrete (SLWAC) with different properties. The study confirmed that the thermal conductivity of $1850 \mathrm{~kg} / \mathrm{m}^{3}$ density of SLWAC ranges from $0.58 \mathrm{~W} / \mathrm{m} \mathrm{K}$ to $0.86 \mathrm{~W} / \mathrm{m} \mathrm{K}$, which is lower than the thermal conductivity of NWC by about $50 \%$ to $70 \%$. The study concluded that the SLWAC has a significant effect on the steady-state condition because of its lower thermal conductivity, and on the unsteady-state conditions because of its higher specific heat capacity. In this research, the whole building energy performance was analyzed using EnergyPlus software program [37]. The total energy usage of the sample in the case study indicated that using SLWAC in construction reduced the annual energy consumption by $0.9 \mathrm{kWh} / \mathrm{m}^{2}$ to $1.3 \mathrm{kWh} / \mathrm{m}^{2}$ (6\% to $11 \%$ saving in energy) compared to usage of NWC. The SLWAC has a significant effect in reduction of heating loads rather than cooling loads because, in the hot climate, the solar gain has more crucial effect on cooling loads than thermal bridges.

Larbi et al. [38] evaluated the performance of an innovative thermal break that can be used in steel balconies attached to a concrete slab. The new thermal break is built of a $10 \mathrm{~mm}$ rigid PVC plate and $10 \mathrm{~mm}$ of acoustic insulation layer. This thermal break is installed between the end-plate of the steel beams and the concrete wall or floor to minimize the impact of the point thermal bridges created by steel beams. A 3-D steady-state simulation analysis using TRISCO was implemented to calculate the point thermal transmittance values by applying different configurations: the thickness of the PVC plate and the insulation layer of the building envelope, the material of fastening parts (stainless steel or carbon steel), and installation of an additional insulation layer around the beams at 
the connection areas. The numerical analysis showed that the innovative thermal break caused a reduction in the impact of the thermal bridge $20 \%$ to $65 \%$ compared to a similar structure built without installing the innovative thermal break. The range of reduction depends on the combination of the construction configurations mentioned above. Moreover, in comparison with carbon steel as a fastening system, stainless steel caused a $17 \%$ to $37 \%$ reduction in the impact of the thermal bridge.

\section{Conclusions}

It is obvious from the published literatures and technical reports that further research and development initiatives are needed to reduce the impact of the balcony thermal bridge on building energy efficiency. Development of innovative thermal breaks, using advanced thermal insulation and structural materials, is a top priority. Moreover, most of the published literatures on thermal bridge and breaks were based on numerical simulation. The lack of experimental benchmarking of simulation results may lead to an under or overestimation of the actual results and the future performance of the buildings.

\section{Acknowledgements}

The support received from The Libyan-North American Scholarship Program (LNASP) and the University of Victoria are greatly acknowledged.

\section{References}

[1] Theodosiou T. G., Papadopoulos A. M. (2008), The impact of thermal bridges on the energy demand of buildings with double brick wall constructions. Energy Build., 40(11), 2083-2089.

[2] Energy Efficiency Trends in Canada 1990 to 2013. 20Sep-2016. Available at: http://www.nrcan.gc.ca/energy/ publications/19030

[3] Šadauskienė J., Ramanauskas J., Šeduikytė L., Daukšys M., Vasylius A. (2015), A simplified methodology for evaluating the impact of point thermal bridges on the high-energy performance of a passive house. Sustainability, 7(12), 16687-16702.

[4] Carbonaro C., Cascone Y., Fantucci S., Serra V., Perino M., Dutto M. (2015), Energy assessment of a PCM-embedded plaster: embodied energy versus operational energy. Energy Procedia, 78, 3210-3215.

[5] RDH Building Science | Making Buildings BetterTM. RDH Building Science. Available at: http://www.rdh.com/.

[6] Roque E., Santos P. (2017), The effectiveness of thermal insulation in lightweight steel-framed walls with respect to its position. Buildings, 7(1), 13.

[7] Building envelope thermal bridging guide released. Available at: https://www.bchydro.com/news/conservation/ 2014/building-envelope-thermal-bridging.html.
[8] Larbi A. B. (2005), Statistical modelling of heat transfer for thermal bridges of buildings. Energy Build., 37(9), 945-951.

[9] Ascione F., Bianco N., de'Rossi F., Turni G., Vanoli G. P. (2012), Different methods for the modelling of thermal bridges into energy simulation programs: Comparisons of accuracy for flat heterogeneous roofs in Italian climates. Appl. Energy, 97 405-418.

[10] Kośny J., Curcija C., Fontanini A. D., Liu H., Kossecka E., A New Approach for Analysis of Complex Building Envelopes in Whole Building Energy Simulations.

[11] Totten P. E., O'Brien S. M., Pazera M. (2008), The effects of thermal bridging at interface conditions. Building Enclosure Science and Technology Meeting, Minneapolis, MN, June 2008.

[12] Olsen L., Radisch N. (2002), Thermal bridges in residential buildings in Denmark. KEA energetická agentura.

[13] Martin K., Erkoreka A., Flores I., Odriozola M., Sala J. M. (2011), Problems in the calculation of thermal bridges in dynamic conditions. Energy Build., 43(2), 529-535.

[14] Erhorn-Kluttig H., Erhorn H. (2009), Impact of thermal bridges on the energy performance of buildings. Inf. Pap. P148 EPBD Build. Platf.

[15] Ibrahim M., Biwole P. H., Wurtz E., Achard P. (2014), Limiting windows offset thermal bridge losses using a new insulating coating. Appl. Energy, 123, 220-231.

[16] Lstiburek J. W. (2007), A bridge too far: thermal bridges - steel studs, structural frames, relieving angles and balconies. ASHRAE J., 49(10), 64.

[17] Kosny J., Christian J. E. (1995), Thermal evaluation of several configurations of insulation and structural materials for some metal stud walls. Energy Build., 22(2), 157163.

[18] Ghazi Wakili K., Simmler H., Frank T. (2007), Experimental and numerical thermal analysis of a balcony board with integrated glass fibre reinforced polymer GFRP elements. Energy Build., 39(1), 76-81.

[19] TRISCO. Available at: http://www.physibel.be/v0n2tr.htm.

[20] Karabulut K., Buyruk E., Fertelli A. (2009), Numerical investigation of heat transfer for thermal bridges taking into consideration location of thermal insulation with different geometries. Stroj. Časopis za Teor. Praksu u Stroj., 51(5), 431-439.

[21] “ANSYS Fluent Software: CFD Simulation.” Available at: //www.ansys.com/products/fluids/ansys-fluent.

[22] Karabulut K., Buyruk E., Fertelli A. (2016), Numerical investigation of the effect of insulation on heat transfer of thermal bridges with different types. Therm. Sci., 20(1), 185-195.

[23] Examples of Structural Thermal Bridges in Buildings Schöck USA Inc. Available at: http://www.schock-us.com/ en_us/examples-of-structural-thermal-bridges-in-buildings.

[24] HEAT3. Available at: http://www.buildingphysics.com/index-filer/Page691.htm.

[25] Ge H., McClung V. R., Zhang S. (2013), Impact of balcony thermal bridges on the overall thermal performance of multi-unit residential buildings: A case study. Energy Build., 60, 163-173.

[26] THERM | Windows and Daylighting. Available: https:// windows.lbl.gov/software/therm. 
[27] eQUEST. Available at: http://www.doe2.com/equest/.

[28] Susorova I., Skelton B. (2016), The effect of balcony thermal breaks on building thermal and energy performance. IBPSA-USA J., 6(1).

[29] Goulouti K., de Castro J., Vassilopoulos A. P., Keller T. (2014), Thermal performance evaluation of fiber-reinforced polymer thermal breaks for balcony connections. Energy Build., 70, 365-371.

[30] Goulouti K., de Castro J., Keller T. (2016), Aramid/glass fiber-reinforced thermal break - thermal and structural performance. Compos. Struct., 136, 113-123.

[31] Murad C., Doshi H., Ramakrishnan R. (2015), Impact of insulated concrete curb on concrete balcony slab. Procedia Eng., 118, 1030-1037.

[32] Ge H., Baba F. (2015), Dynamic effect of thermal bridges on the energy performance of a low-rise residential building. Energy Build., 105, 106-118.

[33] WUFI ${ }^{\circledR}$ Plus | WUFI (en). Available at: https://wufi.de/en/ software/wufi-plus/
[34] Baba F., Ge H. (2016), Dynamic effect of balcony thermal bridges on the energy performance of a high-rise residential building in Canada. Energy Build., 116, 78-88.

[35] Dikarev K., Berezyuk A., Kuzmenko O., Skokova A. (2016), Experimental and Numerical Thermal Analysis of Joint Connection «Floor Slab - Balcony Slabe» with Integrated Thermal Break. Energy Procedia, 85, 184-192.

[36] Real S., Gomes M. G., Moret Rodrigues A., Bogas J. A. (2016), Contribution of structural lightweight aggregate concrete to the reduction of thermal bridging effect in buildings. Constr. Build. Mater., 121, 460-470.

[37] EnergyPlus | EnergyPlus. Available at: https://energyplus. net/.

[38] Ben Larbi A., Couchaux M., Bouchair A. (2017), Thermal and mechanical analysis of thermal break with end-plate for attached steel structures. Eng. Struct., 131, 362-379. 